\title{
Prevalence of depressive symptoms and associated factors among older adults treated at a referral center
}

Abstract

The present study aimed to estimate the prevalence of depressive symptoms and associated factors among older adults treated at a referral center. A cross-sectional study was carried out with a sample of 360 older adults treated at a Referral Center for the Health of Older Adults in the north of Minas Gerais, Brazil. The following data were collected in 2017: demographic, socioeconomic, morbidity, hospital admission in the last year, frailty (Edmonton Frail Scale), functional capacity (Katz Index, Lawton and Brody Scale) and presence of depressive symptoms (Geriatric Depression Scale - GDS-15). Multiple analysis was performed through logistic regression. A prevalence of depressive symptoms was observed in $37.2 \%$ of the sample. The variables associated with depressive symptoms were: negative perception about one's own health (OR=1.9, 95\% CI 1.34-2.70); frailty $(\mathrm{OR}=1.94,95 \% \mathrm{CI} 1.41-2.66)$; having suffered falls (OR=1.24, 95\% CI 1.01-1.61); having been hospitalized in the last year $(\mathrm{OR}=1.56,95 \% \mathrm{CI}, 1.11-2.27)$; $(\mathrm{OR}=2.56,95 \% \mathrm{CI}$ $1.38-4.77)$ and residing alone $(\mathrm{OR}=1.66,95 \% \mathrm{CI} 1.09-2.53)$. Thus, a high prevalence of depressive symptoms was identified among the older adults, evidencing the need for an effective and immediate approach by health professionals.

\footnotetext{
Universidade Estadual de Montes Claros, Centro de Ciências Biológicas e da Saúde, Departamento de Enfermagem. Montes Claros, MG, Brasil.

2 Universidade Estadual de Montes Claros, Centro de Ciências Biológicas e da Saúde, Departamento de Enfermagem, Programa de Pós-Graduação em Cuidado Primário em Saúde. Montes Claros, MG, Brasil.

3 Universidade Estadual de Montes Claros, Centro de Ciências Biológicas e da Saúde, Departamento de Saúde Mental e Saúde Coletiva. Montes Claros, MG, Brasil.

4 Centro Universitário FIPMoc de Montes Claros, Departamento de Medicina. Montes Claros, MG, Brasil.
}

Keywords: Health of the Elderly. Depression. Aging.

No funding was received in relation to the present study.

Authors declare no conflict of interest.

Correspondence

Patrícia Oliveira Silva

Patrícia Oliveira Silval ${ }^{\mathbb{D}}$ Bruna Menezes Aguiar' $\mathbb{1}$ Maria Aparecida Vieira² ${ }^{\mathbb{D}}$ Fernanda Marques da Costa 23,4 (ID Jair Almeida Carneiro, $\mathbb{I D}^{3}$ 


\section{INTRODUCTION}

Depression is the most common mood disorder to affect the mental health of older adults. When underdiagnosed, it can become chronic, causing great psychological distress, functional dependence, isolation, poor quality of life, greater use of health services, and increased risk of death ${ }^{1}$.

In older adults, a major depressive disorder is characterized by the presence of a predominantly depressed or irritable mood and anhedonia. There is a subjective sense of diminished energy, disinterest, slowness, and pessimistic thoughts. In general, these symptoms are accompanied by changes in sleep quality and appetite, cognitive impairment, behavioral and psychosomatic changes, and without treatment the condition can last months or years. Investigating such a disorder is therefore essential, as it can lead to a reduction in the life expectancy and impairment of the autonomy and functional independence of older adults, and a deterioration in quality of life $e^{2,3}$.

It is common for older adults to have an insufficient number of depressive symptoms to diagnose a major depressive disorder. In this case, the term "minor depressive disorder" applies, in which the individual suffers from the presence of the relevant symptoms, but is able to perform most of their activities"-5. The term "clinically significant depressive symptoms" (CSDS) refers to a broad category of depressive symptoms detected using screening scales. Most older adults with CSDS do not meet the criteria for the diagnosis of "major depression" 5 .

In Brazil, the prevalence of major depressive disorder among non-institutionalized older adults varies from $3 \%$ to $15 \%$, while the prevalence of CSDS ranges from $13 \%$ to $39 \%$, indicating a higher prevalence of depressive symptoms than the rates reported in non-Brazilian literature, the average of which is around $13.5 \%{ }^{6-8}$. The disagreement between the observed data highlights the need for further studies, so that the variables identified can be addressed and treated more effectively and immediately by health professionals and managers ${ }^{8}$.
Studies ${ }^{5,-11}$ have illustrated the relationship between depressive symptoms in older adults and sociodemographic factors such as the female gender; advanced age; low education, and the lack of a marital partner. With regard to health conditions, factors described as associated with depressive signs are functional disability; a negative perception of health, smoking; greater use of medicines; insomnia and chronic somatic comorbidities. Despite these aspects described in literature, there are still gaps in knowledge, as there is a lack of studies ${ }^{1,11-13}$ relating to older adults treated in referral services for the health of this population.

Studies ${ }^{5,11-13}$ have shown that frailty associated with aging increases susceptibility to disease and influences the functional capacity of older adults, in addition to generating a negative perception of one's own health, directly compromising the individual's ability to cope with stressful conditions. It is important to identify the self-rated health of the population, as a negative perception of health is described in literature as a predictor of the mortality, functional disability and mental health of older adults $^{1,5,11}$.

In the northern region of the state of Minas Gerais, there are few records of evaluations that address depressive symptoms and associated factors in older adults ${ }^{5,11}$. The assessment of the living and health conditions of this population has the potential to generate new knowledge and support the decision making of health managers. Thus, the present study aimed to estimate the prevalence of depressive symptoms and their associated factors among older adults treated at a referral center.

\section{METHOD}

A cross-sectional and analytical study with a quantitative approach was carried out, with data collected through a structured questionnaire. The scenario of this study was one of the centers of the Mais Vida (More Life) Program located in the north of Minas Gerais. The program is based around an integrated health care network for the older population, with emphasis on Referral Centers 
for the Health Care of Older Adults (or CRASI), with care provided by a multidisciplinary team. The centers provide specialized health care for the older population considered frail or at risk, refererred by a Primary Health Care unit ${ }^{11}$.

The evaluated group was selected through nonintentional convenience sampling, according to the demand for treatment, between May and July 2017, due to the difficulty of random selection. Data were collected primarily through direct contact and interviews with the target population, which took place during the morning and afternoon sessions at CRASI in northern Minas Gerais. The interviewers were previously trained and calibrated (kappa 0.8).

To define the sample size, a calculation was applied based on a conservative prevalence of $50 \%$ (for the occurrence of the symptoms of depressive disorders) and a significance level of $5 \%$, with a confidence interval of $95 \%$ and a tolerable sampling error of $3 \%$. This first estimate of sample size was increased by $20 \%$ to explore the adjusted associations between the independent variables and depressive symptoms.

The inclusion criteria were age 65 and over and be receiving treatment at CRASI, while the exclusion criteria were: being on antidepressants; present cognitive disability, according to the assessment of family members; an uncorrected hearing deficit that hindered the understanding of the questions, and refusal to participate in the study by the older adults or their families. Older adults aged 60 to 64 years were also excluded, as the instrument used to assess frailty has only been validated for those aged 65 years or older ${ }^{5}$.

Cognitive disability based on the assessment of family members was taken as a plausible measure given the complexity of applying the instrument. In this case, before the beginning of the interview, the data collection instrument was presented to the family members, who judged if the older adult would be able to answer it. The data collection instruments used were based on similar studies ${ }^{5,11}$ and were previously tested in a pilot study, the data of which were not included in the final study. A total of 360 older adults participated in the study.
The outcome variable of this study, "depressive symptoms", was obtained by applying the Geriatric Depression Scale (GDS-15) with 15 questions. This instrument has been validated for Brazil and consists of negative and affirmative questions, in which a result of six or more points identifies depressive symptoms. The cutoff point adopted was five for non-cases and six for cases ${ }^{14}$.

The independent variables studied were: gender; age; skin color; marital status; living arrangement; own income; categorized household income; schooling; ability to read; falls in the last 12 months - number of falls and what causes the falls; have a caregiver; frailty and self-perception of health. Variables related to the self-reported chronic morbidities were hypertension, diabetes mellitus, heart disease, arthritis, osteoporosis, stroke and cancer; polypharmacy ${ }^{15}$ (considered to be the concomitant use of five or more medications); hospitalization in the previous year; instrumental activities of daily living (IADL) and basic activities of daily living (BADL).

Frailty was assessed by the Edmonton Frail Scale (EFS), an instrument that assesses nine domains; cognition; health condition; functional independence; social support; use of medication; nutrition; mood; urinary continence and functional performance. These domains are divided into 11 items, with a score from 0 to 17 . For statistical analysis, the scale results were divided into two levels: not frail (final score $\leq 6$ ) and frail (final score $>6)^{16}$.

The BADLs and IADLs were measured by the Katz Index and the Lawton and Brody Scale, respectively. The first scale was used to evaluate BADLs, and consists of six items: bathing; getting dressed; using the bathroom; transfers; controlling continence and feeding oneself. The Katz index establishes a score between 0 and 3 points, with a score of zero meaning the older adult is considered completely independent for BADLs, a score of one meaning the individual needs the help of an accessory (canes, bars, furniture support) to perform activities, two points meaning the older adult needs human help to perform the tasks, and a score of three meaning the older adult is classified as completely dependent in BADLs ${ }^{17}$. 
The Lawton and Brody Scale is made up of nine more complex everyday tasks such as cooking; performing household activities; washing clothes; handling money; going to far-off places; using the telephone; taking medications; making purchases and using means of transport. According to the Lawton and Brody scale, the older adults were classified as independent for IADLs when they obtained a score above 27 points, while those with a maximum score of 26 points were classified as dependent $t^{17,18}$.

The data collected were analyzed. A descriptive analysis of the data was initially performed. Then, the existence of a statistical association between the dependent variable (presence of depressive symptoms, yes or no) and the independent variables was investigated. For this, bivariate analyzes were performed (Pearson's chi-squared test or Fisher's exact test), adopting a significance level of $\leq 0.20$ to include independent variables in the multiple model. The final model was generated by multiple logistic regression analysis and the variables with an association with depressive symptoms were maintained in the final model up to a significance level of $5 \%(p \leq 0.05)$.

The study complied with the ethical principles of National Health Council (or CNS) Resolution No. 466/12 and was approved by the Research Ethics Committee under opinion No. 1,003,534. All the participants were informed about the study and presented their consent, signing a free and informed consent form. When the older adults could not sign, they registered their fingerprints or someone in the family signed the form, allowing the interview for data collection.

\section{RESULTS}

Of the 360 older adults, the predominant age group was between 65 and 79 years (75.3\%), with a mean age of 75 years $(S D \pm 7.6)$. Most of older adults were female $(78.1 \%)$, described having non-white skin color $(69.6 \%)$, being widowed $(42.8 \%)$, living with other family members $(63.6 \%)$, having their own income $(97.5 \%)$, earning more than one minimum wage $(68.0 \%)$, having an elementary education (46.4\%), and being able to read (58.6\%).

Most of the older adults (54.4\%) reported having suffered a fall in the previous 12 months, while $42.8 \%$ of these falls were caused by tripping/slipping, $63.6 \%$ of the older adults were afraid of falling, $67.8 \%$ did not have a caregiver, $47.2 \%$ were frail and $60.6 \% \mathrm{had}$ a negative perception of health.

In relation to aspects of morbidity, it was found that hypertension was the most common chronic disease in older adults (74.7\%), followed by arthritis/rheumatism $(43.9 \%)$, osteoporosis $(34.2 \%)$, heart disease $(21.9 \%)$, diabetics $(20.3 \%)$, a history of strokes $(10.6 \%)$ and cancer $(4.4 \%)$. Polypharmacy was identified in $66.6 \%$ of the older adults, while hospitalization in the previous year was $21.2 \%, 78.6 \%$ were dependent in the performance of IADL and $21.4 \%$ in BADL.

The prevalence of depressive symptoms among older adults treated at CRASI was 37.2\%; 39.1\% among women and $30.4 \%$ among men. For older adults aged 80 years and over, the prevalence was $38.2 \%$; while for younger older adults, aged between 65 and 79 years old, it was $36.9 \%$. The associations between the independent variables and depressive symptoms are presented in Tables 1 and 2. 
Table 1. Bivariate analysis of depressive symptoms among older adults according to sociodemographic variables (N=360). Montes Claros, MG, 2017.

\begin{tabular}{|c|c|c|c|}
\hline \multicolumn{4}{|c|}{ Depression } \\
\hline \multirow[t]{2}{*}{ Independent Variables } & Yes & No & $p$-value \\
\hline & $\mathrm{n}(\%)$ & $\mathrm{n}(\%)$ & \\
\hline \multicolumn{4}{|l|}{ Sex } \\
\hline Male & $55(69.6 \%)$ & $24(30.4 \%)$ & 0.15 \\
\hline Female & $171(69.9 \%)$ & $110(39.1 \%)$ & \\
\hline \multicolumn{4}{|l|}{ Age (years) } \\
\hline Up to 79 & $171(63.1 \%)$ & $100(36.9 \%)$ & 0.82 \\
\hline 80 and over & $55(61.8 \%)$ & $34(38.2 \%)$ & \\
\hline \multicolumn{4}{|l|}{ Skin color } \\
\hline White & $78(57.8 \%)$ & $57(42.2 \%)$ & 0.12 \\
\hline Others & $148(65.8 \%)$ & $77\left(34.2^{\circ} \%\right)$ & \\
\hline \multicolumn{4}{|l|}{ Marital Status } \\
\hline With companion & $98(67.1 \%)$ & $48(32.9 \%)$ & 0.15 \\
\hline Without companion & $128(59.8 \%)$ & $86(40.2 \%)$ & \\
\hline \multicolumn{4}{|l|}{ Living Arrangements } \\
\hline Don't live alone & $179(59.9 \%)$ & $120(40.1 \%)$ & 0.01 \\
\hline Live alone & $47(77.0 \%)$ & $14(23.0 \%)$ & \\
\hline \multicolumn{4}{|l|}{ Has own income } \\
\hline Yes & $221(63.0 \%)$ & $130(37.0 \%)$ & 0.65 \\
\hline Not & $5(55.6 \%)$ & $4(44.4 \%)$ & \\
\hline \multicolumn{4}{|l|}{ Schooling } \\
\hline 5 years or more & $40(78.4 \%)$ & $11(21.6 \%)$ & 0.01 \\
\hline Up to 4 years & $186(60.2 \%)$ & $123(39.8 \%)$ & \\
\hline \multicolumn{4}{|l|}{ Ability to read (can read) } \\
\hline Yes & $134(63.5 \%)$ & $77(36.5 \%)$ & 0.73 \\
\hline Not & $92(61.7 \%)$ & $57(38.3 \%)$ & \\
\hline \multicolumn{4}{|l|}{ Categorized household income } \\
\hline More than 1 minimum wage & $146(59.6 \%)$ & $99(40.4 \%)$ & 0.68 \\
\hline Up to 1 minimum wage & $80(69.6 \%)$ & $35(30.4 \%)$ & \\
\hline
\end{tabular}

Source: Field Research (CRASI), May and June 2017.

Table 2. Bivariate analysis of depressive symptoms among older adults according to health conditions and morbidity (N=360). Montes Claros, MG, 2017.

\begin{tabular}{llll}
\hline Independent Variables & \multicolumn{1}{c}{ Depression } & No \\
& $\begin{array}{l}\text { Yes } \\
\mathrm{n}(\%)\end{array}$ & $\mathrm{n}(\%)$ & -value \\
\hline Hypertension & & $101(37.5 \%)$ & 0.82 \\
Yes & $168(62.5 \%)$ & $33(36.3 \%)$ & 0.96 \\
No & $58(63.7 \%)$ & & $27(37 \%)$ \\
Diabetes & & $107(37.3 \%)$ & to be continued
\end{tabular}


Continuation of Table 2

\begin{tabular}{|c|c|c|c|}
\hline \multirow{3}{*}{ Independent Variables } & \multicolumn{2}{|c|}{ Depression } & \multirow{3}{*}{$p$-value } \\
\hline & Yes & No & \\
\hline & $\mathrm{n}(\%)$ & $\mathrm{n}(\%)$ & \\
\hline \multicolumn{4}{|l|}{ Cardiac disorders } \\
\hline Yes & $48(60.8 \%)$ & $31(39.2 \%)$ & 0.67 \\
\hline No & $178(63.3 \%)$ & $103(36.7 \%)$ & \\
\hline \multicolumn{4}{|l|}{ Cancer } \\
\hline Yes & $8(50.0 \%)$ & $8(50 \%)$ & 0.27 \\
\hline No & $218(63.4 \%)$ & $126(36.6 \%)$ & \\
\hline \multicolumn{4}{|l|}{ Arthritis / Rheumatism } \\
\hline Yes & $97(61.4 \%)$ & $6138.6 \%$ & 0.63 \\
\hline No & $129(63.9 \%)$ & $73(36.1 \%)$ & \\
\hline \multicolumn{4}{|l|}{ Osteoporosis } \\
\hline Yes & $74(60.2 \%)$ & $49(39.8 \%)$ & 0.14 \\
\hline No & $152(64.1 \%)$ & $85(35.9 \%)$ & \\
\hline \multicolumn{4}{|l|}{ Stroke } \\
\hline Yes & $22(57.9 \%)$ & $16(42.1 \%)$ & 0.51 \\
\hline No & $204(63.4 \%)$ & $118(36.6 \%)$ & \\
\hline \multicolumn{4}{|l|}{ Has a caregiver } \\
\hline No & $166(68.0 \%)$ & $78(32 \%)$ & 0.00 \\
\hline Yes & $60(51.7 \%)$ & $56(48.3 \%)$ & \\
\hline \multicolumn{4}{|c|}{ Falls in the previous 12 months } \\
\hline No & $97(59.1 \%)$ & $67(40.9 \%)$ & 0.19 \\
\hline Yes & $129(65.8 \%)$ & $67(34.2 \%)$ & \\
\hline \multicolumn{4}{|c|}{ Hospitalizations in the previous year } \\
\hline None & $171(60.2 \%)$ & $113(39.8 \%)$ & 0.05 \\
\hline One or more & $55(72.4 \%)$ & $21(27.6 \%)$ & \\
\hline \multicolumn{4}{|l|}{ Self-perception of health } \\
\hline Negative & $112(51.4 \%)$ & $106(48.6 \%)$ & 0.00 \\
\hline Positive & $114(80.3 \%)$ & $18(19.7 \%)$ & \\
\hline \multicolumn{4}{|l|}{ Frailty } \\
\hline Not frail & $150(78.9 \%)$ & $40(21.1 \%)$ & 0.00 \\
\hline Frail & $76(44.7 \%)$ & $94(55.3 \%)$ & \\
\hline \multicolumn{4}{|l|}{ Polypharmacy } \\
\hline No & $159(62.2 \%)$ & $81(33.8 \%)$ & 0.05 \\
\hline Yes & $67(55.8 \%)$ & $53(44.2 \%)$ & \\
\hline \multicolumn{4}{|c|}{ Instrumental Activities of Daily Living (IADL) } \\
\hline Up to 26, dependent & $157(55.7 \%)$ & $125(44.3 \%)$ & 0.00 \\
\hline 27 and above, independent & $69(88.5 \%)$ & $9(11.9 \%)$ & \\
\hline \multicolumn{4}{|c|}{ Basic Activities of Daily Living (BADL) } \\
\hline Independent & $187(66.1 \%)$ & $96(33.9 \%)$ & 0.13 \\
\hline Dependent & $39(50.6 \%)$ & $38(49.4 \%)$ & \\
\hline
\end{tabular}

Source: Field Research (CRASI), May and June 2017. 
After multiple logistic regression analysis, the variables that remained associated with depressive symptoms were: negative perception of one's own health (OR=1.9; 95\% CI 1.34-2.70); presence of frailty $(\mathrm{OR}=1.94 ; 95 \%$ CI 1.41-2.66); have suffered falls $(\mathrm{OR}=1.24 ; 95 \%$ CI 1.01-1.61); have been hospitalized in the last year (OR=1.56; 95\% CI 1.11-2.27); have functional disability for the performance of IADLs $(\mathrm{OR}=2.56 ; 95 \%$ CI 1.38-4.77) and reside alone $(\mathrm{OR}=1.66 ; 95 \%$ CI 1.09-2.53).

\section{DISCUSSION}

In the present study, the prevalence of depressive symptoms was high, $37.2 \%$, when compared to population-based studies conducted in Florianópolis, Santa Catarina ${ }^{1}$, Pelotas, Rio Grande do Sul ${ }^{19}$, and northern Minas Gerais ${ }^{5}$, which presented lower values than those observed in this study, using the same instrument (GDS-15). However, the prevalence of depressive symptoms in community-dwelling older adults is lower than that observed among the older adults treated at CRASI, possibly due to the clinical profile of referral to the service, according to the criteria of the Older Adults Health Care Network ${ }^{12,20}$.

Studies that investigated the prevalence of depressive symptoms in older adults treated at referral centers in Brazil revealed a prevalence ranging from $7.1 \%$, with 313 older adults based on a screening performed in Passo Fundo, Rio Grande do Sul ${ }^{13}$, to $30.9 \%$ based on a survey of 317 older adults in the city of Uberaba, Minas Gerais ${ }^{12}$. Part of this disparity between findings is due to the methodology, the instrument used in the research, the inclusion criteria, the peculiarities of each region and the way of measuring data, which may interfere with the final results of the study.

Non-Brazilian data also varies due to the instruments and population evaluated. A study conducted in New York ${ }^{21}$ with 378 older patients found a prevalence of depressive symptoms in older adults of $31.0 \%$, based on the Patient Health Questionnaire-9 (PHQ-9). A German study ${ }^{22}$ that used GDS-15 with around 3,300 older adults reported a prevalence of $9.7 \%$. Another Japanese study ${ }^{23}$, using the same scale with 5,400 community-dwelling older adults, reported a prevalence of $33.5 \%$.
The prevalences found by the studies, regardless of their variations, highlight the significance of the theme. It also suggests that screening criteria are not being followed or that the criteria may need to be reevaluated, especially considering the clear process of population aging in Brazil and around the world ${ }^{5,24}$. The factors associated with depressive symptoms found in this study determine the risk of such symptoms based on health conditions (negative perception of one's own health, being frail, having suffered falls, being hospitalized in the previous year and inability to perform IADL).

The negative perception of one's own health was associated with depressive symptoms, as it was in other studies ${ }^{5,25,26}$. As it is a subjective assessment, self-perception of health has a multidimensional character, as the way individuals view their health status will determine their behavior, choices and way of living ${ }^{25}$. With the loss of cognitive, sexual and work functions, the decrease of social relations and the feeling of disability, among other elements, influence both a worse perception of health and the occurrence of depressive symptoms. ${ }^{19}$.

Perception of health is an important marker of biological, psychological and social dimensions and is useful for assessing quality of life. Studies have shown that the individual's own reporting of poor health can be understood as a depressive symptom ${ }^{1,5}$.

Depressive symptoms were associated with the presence of frailty, a similar result to that identified in other studies that also tracked frailty through the $\mathrm{EFS}^{27-29}$. Greater frailty was expected in this study, since frail older adults receive an absolute recommendation for a specialized, multidimensional and multidisciplinary assessment, according to the criteria of the older adults health care network where data collection was performed ${ }^{20}$.

Frailty has been defined as a syndrome of declining energy, based on changes that occur with aging, manifesting itself as a reduction in gait speed; weight loss; fatigue; decreased grip strength and low levels of physical activity. Thus, frailty has the potential to affect every aspect of the life of older adults leaving them vulnerable to depressive symptoms. In addition, it is an event whose effects extend beyond the older adult and may cause family and caregiver burden. ${ }^{5,27-28}$. 
The occurrence of falls among older adults proved to be a risk for depressive symptoms, as in other similar studies ${ }^{17,27-29}$. Research ${ }^{17,29}$ has pointed out the relationship between the presence of frailty, the use of drugs and falls among older adults, which may occur due to inappropriate dosages, adverse effects and drug interactions.

The costs and implications of falls among older adults are significant for the individual, due to physical and psychological trauma, which, in addition to causing possible fractures, can also cause a fear of falling again, a loss of confidence, and a restriction of activities of daily living, as well as declining health and the increased risk of institutionalization. These limitations cause impairment in the movement of the individual, causing social isolation and the possible triggering of depressive symptoms ${ }^{19,29}$.

The presence of depressive symptoms was associated with hospitalization in this and other studies $^{7,30}$. Although the presence of noncommunicable chronic diseases (NCDs) is not always accompanied by depressive symptoms, their cumulative harmful effects during the aging process lead to a higher risk of adverse health events. The difficulty in carrying out a correct diagnosis is due to conditions directly associated with increased morbidity and mortality in the older adult population, as well as a greater demand for health services and length of hospital bed occupancy. Remaining in hospital may be considered a risk factor for depressive symptoms ${ }^{7}$.

The relationship between depressive symptoms and functional dependence, whether for BADL or IADL, has been extensively described in literature ${ }^{11,28,30,31}$. Functional capacity is an important marker of aging and the quality of life of older adults. With functional decline depressive symptoms may appear, due to the physical, social and functional impairment of the individual, leading to important health complications that can directly interfere with the onset of depressive symptoms ${ }^{28,30}$.

It is noteworthy that the present study found an association between depressive symptoms and dependence in IADLs. These activities require greater physical and cognitive integrity as they are related to the social participation of the subject, such as shopping, answering the telephone and using means of transportation ${ }^{28}$. The loss of autonomy and limitations in daily living generate an imbalance in emotions, well-being and social image and may trigger depressive symptoms ${ }^{11}$.

Regarding sociodemographic aspects, the condition of living alone was associated with depressive symptoms. Similar studies ${ }^{13,29,30}$ have identified that older adults who live alone have a greater perception of loneliness, either through grief, social isolation or abandonment. From the point of view of life experience, older adults experience a situation of continued loss, and these losses often arouse feelings of discouragement and sadness that eventually lead to depressive symptoms. Conditions of social and family support may influence the onset of depressive symptoms among older adults, as well as the poor prognosis of existing comorbidities, which may contribute to higher mortality, either due to the increased risk of suicide or the evolution of chronic diseases ${ }^{11}$.

Despite their high prevalence, depressive symptoms are poorly investigated and underdiagnosed in the older adult population. Thus, the geriatric approach should go beyond conventional strategies, with a curative focus, aimed at the promotion of mental health and the prevention of the occurrence of depressive symptoms, with the proper identification of health problems and related risk factors ${ }^{4,7-8}$.

It is essential to offer an approach aimed at healthy aging, to understand how the phenomena present themselves and to ensure the care of the needs of older adults from an integral and multidimensional perspective. The use of screening tools for depressive symptoms will not only help in identifying cases, but will also directly influence the planning and implementation of actions with a possible impact on the quality of life of the older adults ${ }^{31}$.

Some limitations should be considered when reflecting on the results of this study. The research involved a sampling process, in which the external validity is limited and the results can be extrapolated only to a similar population. The identification of morbidities was performed by self-reporting, which may have led to an underestimation of the actual prevalence of conditions of morbidity and the assessment of cognitive ability according to 
the opinion of family members. However, the present study has a sufficiently large sample to adjust the regression models to the main factors of clinical interest and used standardized instruments validated in Brazil.

\section{CONCLUSION}

The present study identified a high prevalence of depressive symptoms in older adults treated at a Referral Center in northern Minas Gerais. The results of this study show the need for an effective and immediate approach from health professionals in relation to older adults who especially exhibit a negative perception of their own health; frailty; who have suffered falls; were hospitalized in the previous year; who are unable to perform IADLs and who reside alone. Further studies are needed in this area, and may contribute new scientific evidence that will allow early and effective interventions focusing on the mental health of older adults.

Edited by: Tamires Carneiro Oliveira Mendes

\section{REFERENCES}

1. Borges LJ, Benedetti TRB, Tania RB, Xavier AJ, D'orsi E. Fatores associados aos sintomas depressivos em idosos: estudo EpiFloripa. Rev Saúde Pública. 2013;47(4):701-10.

2. Lentsck MH, Pilger C, Schoereder EP, Prezotto KH, Mathias TAF. Prevalência de sintomas depressivos e sinais de demência em idosos na comunidade. Rev Eletr Enferm. 2015;17(3):1-9.

3. González ACT, Ignácio ZM, Jornada LK, Réus GZ, Abelaira HM, Santos MAB, et al. Transtornos depressivos e algumas comorbidades em idosos: um estudo de base populacional. Rev Bras Geriatr Gerontol. 2016;19(1):95-103.

4. Lopes LO, Cachioni M. Impacto de uma intervenção psicoeducacional sobre o bem-estar subjetivo de cuidadores de idosos com doença de Alzheimer. Temas Psicol. 2013;21(1):165-81.

5. Ramos GCF, Carneiro JA, Barbosa ATF, Mendonça JMG, Caldeira AP. Prevalência de sintomas depressivos e fatores associados em idosos no norte de Minas Gerais: um estudo de base populacional. J Bras Psiquiatr. 2015;64(2):122-31.

6. Girondi JBR, Nothaft SCS, Santos SMA, Oliveira F, Sebold LF, Kempfer SS. Estudo do perfil de morbimortalidade entre idosos. Rev Enferm UFSM. 2013;3(2):197-204.

7. Cohen R, Paskulin LMG, Prieb RGG. Prevalência de sintomas depressivos entre idosos em um serviço de emergência. Rev Bras Geriatr Gerontol. 2015;18(2):307-17.

8. Gritti CC, Bene AZ, Pinheiro DM, Bianchin MA, Lamari NM. Doenças crônicas não transmissíveis e antecedentes pessoais em reinternados e contribuição da terapia ocupacional. Cad Saúde Colet. 2015;23(2):214-9.

9. Fontes AP, Fattori A, D’elboux MJ, Guariento ME. Resiliência psicológica: fator de proteção para idosos no contexto ambulatorial. Rev Bras Geriatr Gerontol. 2015;18(1): 7-17.

10. Silva ER, Sousa ARP, Ferreira LB, Peixoto HM. Prevalência e fatores associados à depressão entre idosos institucionalizados: subsídio ao cuidado de enfermagem. Rev Esc Enferm USP. 2012;46:1387-93.

11. Hoffmann EJ, Ribeiro F, Farnese JM, Lima EWB. Sintomas depressivos e fatores associados entre idosos residentes em uma comunidade no norte de Minas Gerais, Brasil. J Bras Psiquiatr. 2010;59(3):190-7.

12. Soares PPB, Reis NA, Peixoto BG, Gonçalves AR, Amaro EA, Gonçalves JRL. Prevalência de indicativos de depressão em idosos de uma unidade de atenção ao idoso. REFACS. 2017;5(2):289-96.

13. Piani MC, Alves ALS, Bervian J, Graeff DB, Pancotte J, Doring M, et al. Prevalência de sintomas depressivos em idosas de um Centro de Referência de Atenção ao Idoso no município de Passo Fundo, Rio Grande do Sul. Rev Bras Geriatr Gerontol. 2016:19(6):930-8.

14. Almeida OP, Almeida SA. Confiabilidade da versão brasileira da Escala de Depressão em Geriatria (GDS) versão reduzida. Arq Neuropsiquiatr. 1999;57(2B):421-6.

15. Pereira KG, Peres MA, Iop D, Boing AC, Boing AF, Aziz M, et al. Polifarmácia em idosos: um estudo de base populacional. Rev Bras Epidemiol 2017; 20(2)335-344.

16. Rolfson DB, Majumdar SR, Tsuyuki RT, Tahir A, Rockwood K. Validity and reliability of the Edmonton Frail Scale. Age Ageing. 2006; 35(5):526-9.

17. Duarte YAO, Andrade CL, Lebrão ML. O Índex de Katz na avaliação de funcionalidade dos idosos. Rev Esc Enferm USP. 2007;41(3):317-25. 
18. Lawton MP, Brody EM. Assesment of older people: self-maintaining and instrumental activities of daily living. Gerontologist. 1969;9(3):179-85.

19. Hellwig N, Munhoz TN, Tomasi E. Sintomas depressivos em idosos: estudo transversal de base populacional. Rev Ciênc Saúde Colet. 2016;21(11):3575-84.

20. Minas Gerais. Resolução SES no 2.603, de 07 de dezembro de 2010. Dispõe sobre o Programa Mais Vida - Rede de Atenção a Saúde do Idoso de Minas Gerais, e dá outras providências. Belo Horizonte: SES; 2010.

21. Richardson TM, Friedman B, Podgorski C, Knox K, Fisher S, He H, et al. Depression and its correlates among older adults accessing aging services. J Geriatr Psychiatr. 2012;20(4):346-54.

22. Weyerer S, Eifflaender-Gorfer S, Köhler L, Jessen F, Maier W, Fuchs A, et al. Prevalence andrisk factors for depression in non-demented primary care attenders aged 75 years and older. J Affect Disord. 2008;111(2-3):153-63.

23. Wada T, Ishine M, Sakagami T, Okumiya K, Fujisawa M, Murakami S, et al. Depression in Japanese community-dwelling elderly - prevalence and association with ADL and QOL. Arch Gerontol Geriatr 2004; 39(1):15-23.

24. Duarte MB, Rego MAV. Comorbidade entre depressão e doenças clínicas em um ambulatório de geriatria. Cad Saúde Pública. 2007;23(3):691-700.
25. Silva IT, Pinto Junior EP, Vilela ABA. Autopercepção de saúde de idosos que vivem em estado de corresidência. Rev Bras Geriatr Gerontol. 2014;17(2):275-87.

26. Jerez-Roig J, Souza DLB, Andrade FLJP, Lima Filho BF, Medeiros RJ, Oliveira NPD, et al. Self-perceived health in institutionalized elderly. Ciênc Saúde Colet. 2016;21(11):3367-75.

27. Carneiro JA, Cardoso RR, Durães MS, Guedes MCA, Santos FL, Costa FM, et al. Frailty in the elderly: prevalence and associated factors. Rev Bras Enferm. 2017;70(4):747-52.

28. Freitas CV, Sarges ESNF, Moreira KECS, Carneiro SR. Evaluation of frailty, functional capacity and quality of life of the elderly in geriatric outpatient clinic of a university hospital. Rev Bras Geriatr Gerontol. 2016;19(1):119-28.

29. Paskulin LMG, Bierhals CCBK, Santos NO, Day CB, Machado DO, Morais EP, et al. Depressive symptoms of the elderly people and caregiver's burden in home care. Invest Educ Enferm. 2017;35(2):210-20.

30. Smith PD, Becker K, Roberts L, Walker J, Szanton SL. Associations among pain, depression, and functional limitation in low-income, home-dwelling older adults: an analysis of baseline data from CAPABLE. Geriatr Nurs. 2016;35(5):348-52.

31. Possatto JM, Dóris FR. Condições de saúde psicológica, capacidade funcional e suporte social de idosos. Rev Kairós Gerontol. 2017;20(2):45-58. 